\title{
Presencia de ADN bacteriano en el tejido valvular de pacientes con cardiopatía reumática crónica
}

\author{
Fernando E Figueroa ${ }^{1}$, Flavio Carrión $\mathrm{A}^{\text {la }}$, \\ Sylvia Valenzuela $\mathrm{M}^{1 \mathrm{~b}}$, Eduardo Turner $\mathrm{G}^{2}$, Cristian Aceitón $\mathrm{E}^{\mathrm{lc}}$, \\ Carolina Hirigoyen $\mathrm{P}^{1 \mathrm{~d}}$, Katherine Bogdanic $\mathrm{W}^{1 \mathrm{~d}}$, \\ Claudia Solís D ${ }^{1 d}$, Karina Mansilla $A^{1 b}$, Soledad U rra G ${ }^{3 b}$. \\ Presence of bacterial DNA \\ in valvular tissue of patients \\ with rheumatic heart disease
}

Background: Rheumatic heart disease (RHD) is a delayed consequence of a pharyngeal infection with Group A streptococcus (GAS), usually ascribed to a cross-reactive immune response to the host cardiac tissues. Acute rheumatic fever (ARF) and its ensuing valvular sequelae are thus considered the prototype of a post-infectious autoimmune disease, with no direct evidence of residual streptococcal antigen in diseased valvular tissues. However, recent studies concerning the antigenic specificity and clonality of intralesional lymphocytes have revealed oligoclonal expansions characteristic of an antigen specific response, that might be related to GAS. Aim: To search for bacterial DNA in valvular tissue from RHD patients and controls. Material and methods: We extracted DNA from surgically excised valve specimens from 15 RHD patients and 6 non RHD controls and tested for the presence of bacterial DNA by Polymerase Chain Reaction (PCR) with primers for 16S rRNA. Results: Eighty percent (12/15) of valve specimens from RHD patients were positive for bacterial DNA, as opposed to none of the valves $(n=6)$ from non RHD controls. Conclusions: These results suggest that GAS might persist in valvular tissue in patients with $\mathrm{ARF}$ and contribute to the inflammatory scarring lesion that leads to cardiovascular sequelae (Rev Méd Chile 2007; 135: 959-66).

(Key w ords: DNA, bacterial; Rheumatic heart disease; Streptococcus)

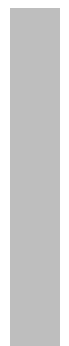

Recibido el 9 de mayo, 2006. Aceptado el 25 de enero, 2007.

Este trabajo fue financiado por el Fondo de Ayuda a la Investigación de la Universidad de los Andes, Proyectos Med-002-98 y Med-005-02.

${ }^{1}$ Laboratorio de Inmunología, Facultad de Medicina, Universidad de los Andes. ${ }^{2}$ Departamento de Cardiología, Instituto Nacional del Tórax y Clínica Alemana. Santiago, Chile. ${ }^{3}$ Facultad de Ciencias Biológicas, Pontificia Universidad Católica de Chile.

aBioquímico, Doctor en Ciencias Biológicas.

bBioquímico.

'Químico Laboratorista.

dEstudiante de Medicina, Universidad de los Andes.

Correspondencia a: Dr. Femando Figueroa E. Facultad de Medicina,

Universidad de los Andes. Av. San Carlos de Apoquindo 2200, Las

Condes. Santiago. Fono: 4129477. Fax: 2141752.

E mail: ffigueroa@uandes.cl 
a carditis reumática es la enfermedad cardíaca adquirida más frecuente en niños y adultos jóvenes en el mundo ${ }^{1}$. Su complicación más grave es la cardiopatía reumática crónica (CRC), que todavía es una causa de importante morbimortalidad en nuestro país ${ }^{2,3}$. La reparación de sus secuelas valvulares representa la primera causa de cirugía cardíaca en los países en vías de desarro$1 o^{4}$.

Está establecido que la CRC ocurre como consecuencia de los episodios agudos de enfermedad reumática (ERA), los que se desencadenan por una infección de la faringe por estreptococo ß-hemolítico grupo A (EBGA) ${ }^{5,6}$. Sin embargo, al cabo de décadas de investigaciones, aún no se esclarecen los mecanismos por los cuales el EBGA conduce a la CRC y a sus secuelas valvulares ${ }^{7}$. Estudios clásicos han demostrado que la respuesta inmune en pacientes con ERA, se caracteriza porque sus componentes celulares ${ }^{8}$ y humorales ${ }^{9}$ reconocen tanto al EBGA como al tejido cardíaco humano ${ }^{10,11}$. Este fenómeno de reactividad cruzada es el fundamento de la teoría de la mímica molecular, que invoca la semejanza estructural entre el agente causal y los tejidos del huésped como mecanismo desencadenante de autoinmunidad $^{12}$. Debido a esto, la ERA se ha considerado el prototipo de enfermedad autoinmune por mímica molecular ${ }^{13,14}$. En consecuencia, sería la reactividad contra autoantígenos cardíacos la que explica que se detecte la presencia de infiltrado celular hasta 20 años después del ataque agudo de la enfermedad, en las válvulas de pacientes con $\mathrm{CRC}^{15,16}$. Sin embargo, resulta llamativo que este infiltrado inflamatorio tan duradero, permanece oligoclonal al cabo de los años ${ }^{17}$. Por otra parte, el estudio de los linfocitos intralesionales demuestra expansiones clonales sugerentes de una respuesta antígeno específica, incluida la restricción por moléculas del complejo mayor de histocompatibilidad ${ }^{18}$.

Por estas razones, planteamos que el EBGA pudiese efectivamente persistir en el tejido valvular de pacientes con CRC y abordamos esta hipótesis investigando, mediante la reacción de polimerasa en cadena (PCR), la presencia de ADN bacteriano en las válvulas de pacientes con CRC sometidos a cirugía de reemplazo valvular.

\section{PACIENTES Y MÉTODO}

Pacientes y material valvular. Se analizaron muestras de tejido valvular de 15 pacientes con CRC sometidos a cirugía de reemplazo valvular en el hospital de Dipreca y en el Instituto Nacional del Tórax, en Santiago. El grupo consistió en 10 mujeres y 5 hombres, con promedio de edad de 55 años, rango: 39-74 años. Todos cumplían criterios clínicos y ecocardiográficos característicos de CRC previamente descritos ${ }^{19,20}$, incluyendo la presencia de enfermedad mitral o mitro-aórtica, con calcificaciones valvulares, fusión comisural, 0 ambos. Como muestras control se estudiaron las válvulas de 6 pacientes no reumáticos (3 mujeres y tres hombres, con promedio de edad 46 años; rango 21-66), sometidos a cirugía por estenosis cálcica o valvulopatía congénita. Ninguno de ellos tenía antecedentes de ERA. Los procedimientos y consentimientos fueron aprobados por el Comité de Ética de la Facultad de Medicina de la Universidad de los Andes. Todos los especímenes valvulares se coleccionaron en forma estéril durante el acto quirúrgico y se procesaron en el plazo de dos horas.

Extracción de ADN. Cada muestra de tejido valvular se disgregó y transfinó a $1 \mathrm{ml}$ de buffer de digestión (500 $\mu \mathrm{M}$ Tris, $20 \mu \mathrm{M}$ EDTA, $10 \mathrm{mM} \mathrm{NaCl}, 1 \%$ dodecilsulfato de sodio) con $0,5 \mathrm{mg} / \mathrm{ml}$ de proteinasa $\mathrm{K}$ para incubación durante $16 \mathrm{~h}$ a $60^{\circ} \mathrm{C}^{21}$. Luego de centrifugar las muestras a 900 x g por 6 min, se añadió al sobrenadante $1 \mathrm{ml}$ de DNAzol reagent (Invitrogen, Life Technologies. Glasgow, Reino Unido) para volver a centrifugar a $10.000 \mathrm{x} \mathrm{g}$ durante $10 \mathrm{~min}$. El ADN se precipitó con etanol al 100\% y se incubó por $3 \mathrm{~min}$, centrifugándose luego a 4.000 x g por $2 \mathrm{~min}$. Este procedimiento se repitió 2 veces con etanol al $75 \%$. Finalmente, el ADN se solubilizó en agua ultrapura (Invitrogen, Life Technologies. Glasgow, Reino Unido) y las muestras se almacenaron a $-45^{\circ} \mathrm{C}$ hasta su análisis.

Amplificación por PCR. Para la amplificación del ADN se emplearon partidores universales para la región 16S rARN cuya secuencia específica es: $16 \mathrm{~S}$ rARN F-5'GAG GAA GGT GGG GAT GAC GT3' y $16 S$ rARN R-5'AGG CCC GGG AAC GTA TTC $\mathrm{AC}^{121,22}$. Estos partidores generan un producto de PCR de 216 pares de bases (pb). El volumen final 
para la reacción de PCR fue de $50 \mu \mathrm{l}$ y contiene los siguientes reactivos: buffer $1 \mathrm{X}, \mathrm{MgCl}_{2} 2,5 \mathrm{mM}, 200$ $\mathrm{mM}$ de cada deoxinucleótido trifosfato dNTP (dATP, dTTP, dCTP, dGTP), 1,25 U Taq ADN polimerasa (Invitrogen). Esta mezcla se incubó en presencia de ADNsa I (Invitrogen) durante $60 \mathrm{~min}$ a $37^{\circ} \mathrm{C}$ y 30 min a $90^{\circ} \mathrm{C}$. Este procedimiento se realizó para minimizar el riesgo de contaminación de los reactivos ${ }^{23}$. Luego, se agregó a la mezcla $1 \mu \mathrm{l}(0,2$ $\mathrm{mM})$ de cada partidor y $5 \mu \mathrm{l}$ del ADN extraído. La reacción de amplificación se realizó en un termociclador Perkin Elmer GeneAmp PCR System 2400. Las muestras fueron amplificadas por 40 ciclos (1 $\min$ a $94^{\circ} \mathrm{C}, 1 \min$ a $58^{\circ} \mathrm{C}$ y $1 \min$ a $72^{\circ} \mathrm{C}$ ) con un paso de extensión final de $10 \mathrm{~min}$ a $72^{\circ} \mathrm{C}^{22-24}$.

Control de la técnica de PCR. La amplificación de un fragmento del gen para la hormona de crecimiento (HC) se utilizó como control de la eficiencia de la reacción de PCR. Los partidores fueron: HC R- 5'ATC CAC TCA CGG ATT TCT GTT GTG TTT C3' y HC F5'CAG TGC CTT CCC AAC CAT TCC CTT A3'. El volumen final de reacción fue $50 \mu \mathrm{l}$, con $5 \mu \mathrm{l}$ del ADN, 0,2 mM de cada dNTP, buffer PCR estándar, 2 $\mathrm{mM} \mathrm{MgCl}_{2}, 2 \mathrm{U}$ de Taq ADN polimerasa (Invitrogen) y $100 \mathrm{ng}$ de cada partidor. Las condiciones de reacción fueron las siguientes: $94^{\circ} \mathrm{C}$ por $5 \mathrm{~min}$; 35 ciclos de $94^{\circ} \mathrm{C}$ de $45 \mathrm{~s} ; 60^{\circ} \mathrm{C}$ de $30 \mathrm{~s} ; 72^{\circ} \mathrm{C}$ por $30 \mathrm{~s}$; la extensión final fue de $72^{\circ} \mathrm{C}$ por $7 \mathrm{~min}$. Como control positivo bacteriano se usó ADN de una cepa de EBGA (Streptococcus pyogenes). Adicionalmente, en cada experimento se incluyeron muestras blanco» con todos los reactivos de la reacción de PCR, exceptuando el ADN del tejido valvular.

Detección del producto de PCR. Los productos de PCR se separaron por electroforesis durante $90 \mathrm{~min}$ a 100 Volts en gel de agarosa al 2,0\% y se tiñeron con bromuro de etidio $(0,05 \mu \mathrm{g} / \mathrm{ml})$. Los resultados se analizaron con el software Kodak Electrophoresis Documentation and Analysis System 120.

\section{RESULTADOS}

La Tabla 1 resume las características clínicas de los pacientes con CRC e indica qué válvulas se investigaron y en cuáles se detectó positividad para ADN bacteriano en la reacción de PCR. Como puede verse, se detectó $\mathrm{ADN}$ bacteriano en 12 de las 15 muestras de valvulopatía reumática investigadas (80\%). Las Figuras 1-A y 2-A ilustran el resultado de la reacción de PCR en las 15 válvulas de pacientes con CRC y la negatividad de todas las válvulas de pacientes con cardiopatía no reumática $(\mathrm{n}=6)$. Se incluyen los controles positivos para ADN bacteriano y los blancos en cada caso. La negatividad de los blancos es imprescindible para descartar contamina-

Tabla 1. Resumen de las características clínicas de los pacientes con CRC y resultado de la detección de AD N bacteriano en las muestras valvulares

\begin{tabular}{|lccccccccccccccc|}
\hline Paciente $\mathrm{N}^{\circ} \rightarrow$ & 1 & 2 & 3 & 4 & 5 & 6 & 7 & 8 & 9 & 10 & 11 & 12 & 13 & 14 & 15 \\
\hline Edad (años) & 55 & 48 & 59 & 61 & 58 & 39 & 62 & 54 & 39 & 44 & 49 & 74 & 51 & 73 & 59 \\
Antecedentes ERA & + & + & - & - & - & - & - & + & - & + & + & - & - & - & - \\
Endocarditis infecciosa & - & - & - & - & - & - & - & - & - & - & - & - & - & - & - \\
Válvulas afectadas & & & & & & & & & & & & & & & \\
Mitral & + & + & + & + & + & + & + & + & + & + & + & + & + & + & + \\
Aórtica & + & + & + & + & + & + & - & + & + & + & + & + & + & - & + \\
Tricúspide & - & + & - & + & - & + & - & - & + & - & + & - & - & - & - \\
Criterios morfológicos & & & & & & & & & & & & & & & \\
Engrosamiento valvas & + & + & + & + & + & + & + & + & + & + & + & + & + & + & + \\
Calcificación valvas & + & + & + & - & + & + & + & + & + & + & + & + & - & + & + \\
Fusión comisuras & + & + & + & + & + & - & + & - & - & - & + & - & - & + & - \\
Detección bacteriana & & & & & & & & & & & & & & & \\
Válvula estudiada & $\mathrm{Mi}$ & $\mathrm{Mi}$ & $\mathrm{Ao}$ & $\mathrm{A} 0$ & $\mathrm{Mi}$ & $\mathrm{Mi}$ & $\mathrm{Mi}$ & $\mathrm{Mi}$ & $\mathrm{Mi}$ & $\mathrm{A} 0$ & $\mathrm{Mi}$ & $\mathrm{Mi}$ & $\mathrm{Mi}$ & $\mathrm{Mi}$ & $\mathrm{Mi}$ \\
Resultado 16S rARN & + & + & + & + & - & + & + & - & - & + & + & + & + & + & + \\
\hline
\end{tabular}

Abreviaturas: Mi: Válvula mitral, Ao: Válvula aórtica, $+=\mathrm{Si},-=$ No. 


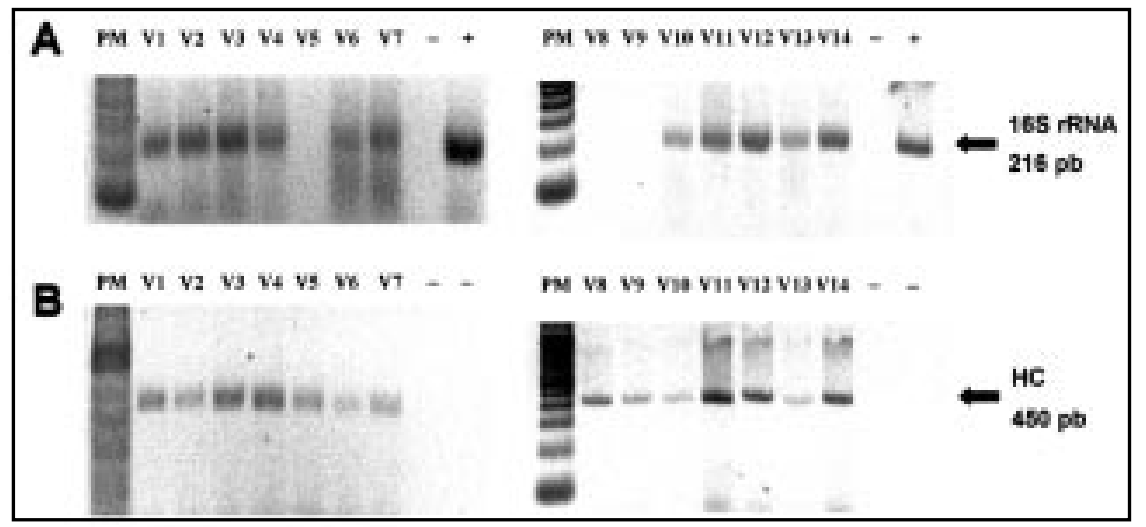

Figura 1. Productos de PCR en gel de agarosa al 2\% para ADN bacteriano en 14 pacientes (V1 a V14) con valvulopatía reumática. Figura 1A: productos de PCR para 16Ss rARN de las válvulas de 14 pacientes reumáticos. Figura 1B: Control con hormona de crecimiento (HC) (V1-V14). PM: estándar de peso molecular; (-): Blanco; (+): Control positivo (EBGA).

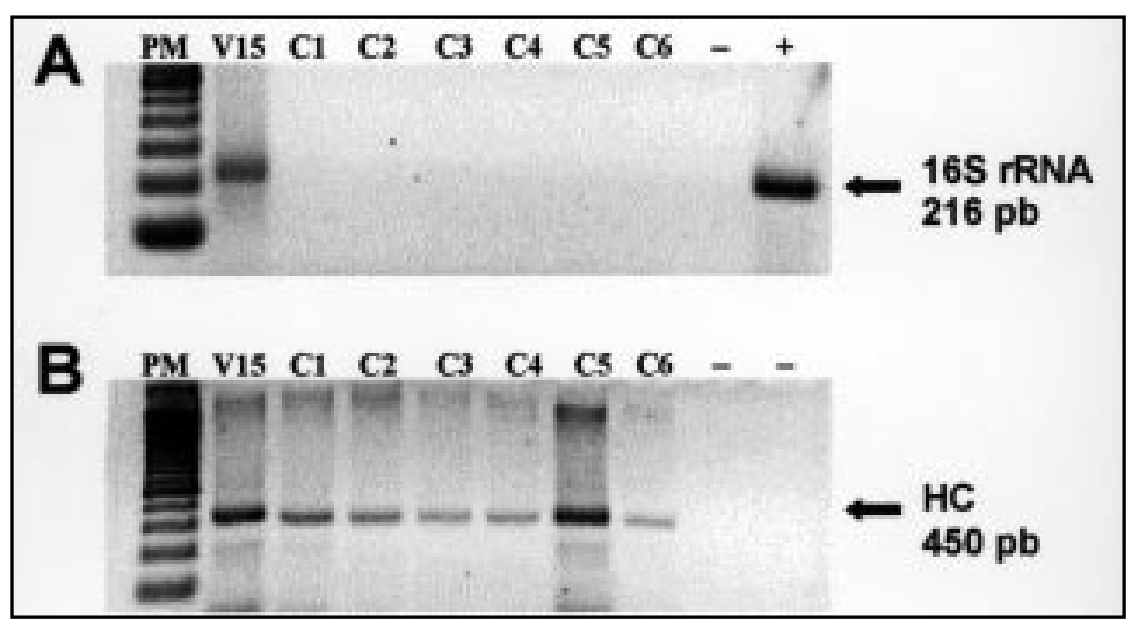

Figura 2. Productos de PCR en gel de agarosa al 2\% para ADN bacteriano en 6 pacientes con valvulopatía no reumática (C1 a C6) y un paciente con valvulopatía reumática (V15). Figura 2A: productos de PCR para 16S rARN de 1 válvula de un paciente reumático (V15) y 6 válvulas de pacientes no reumáticos (C1-C6). Figura 2B: Control hormona de crecimiento (HC). PM: Estándar de peso molecular; (-): Blanco; (+): Control positivo (EBGA).

ciones con ADN bacteriano, debido a la alta sensibilidad de esta técnica. Las Figuras 1-B y 2-B ilustran el control interno de la reacción de PCR con hormona de crecimiento.

\section{DisCUSIÓN}

Está establecido que las manifestaciones cardiovasculares de la enfermedad reumática se desencadenan por una infección de la faringe por $\mathrm{EBGA}^{25}$. En la mayoría de los casos, la enfermedad se resuelve sin secuelas, pero la carditis reumática, que se considera su manifestación más grave, conduce a un fenómeno inflamatorio y daño valvular permanente en $35 \%$ a $79 \%$ de los casos ${ }^{26}$. Los pacientes que evolucionan con valvulopatía crónica usualmente presentan recurrencias de la infección estreptocócica ${ }^{27}$, sin embargo los mecanismos por los que esta infección genera un fenómeno inflamatorio persistente, aún no consiguen aclararse ${ }^{28}$. Son de interés a este respecto las observaciones pros- 
pectivas publicadas por el grupo de Zabriskie y cols en la Universidad de Rockefeller. En un grupo de 87 pacientes con enfermedad reumática sin valvulopatía inicial, la mitad de los individuos desarrolló daño valvular durante un seguimiento a 20 años, sin presentar evidencia clínica ni de laboratorio de infección estreptocócica ${ }^{29}$. Estos datos sugieren que la destrucción del tejido valvular en la CRC puede ser la consecuencia de un proceso que persiste incluso muchos años después del factor desencadenante inicial. En el siglo pasado, se intentó explicar este fenómeno por una invasión directa de los tejidos por el germen responsable. En los estudios de autopsia realizados en 1940 por Thomson y cols, se logró recuperar organismos viables desde las válvulas ${ }^{30}$, pero posteriormente estos resultados no pudieron ser confirmados $^{31}$. Como explicación de estas discrepancias, se planteó la presencia de formas L del EBGA sin pared celular ${ }^{32}$. En épocas más recientes, Raizada y cols describieron preponderancia de linfocitos $\mathrm{T}$ en 25\%-30\% de las válvulas de CRC, hasta 10 a 20 años después del brote agudo de la enfermedad, pero no detectaron la presencia del EBGA al estudiar las válvulas mediante inmunofluorescencia indirecta ${ }^{33}$. Fue con esta técnica que Kaplan describió en la década de 1960-69 la reactividad cruzada de los sueros antiestreptocócicos con las fibras miocárdi$\operatorname{cas}^{34,9}$. La observación más interesante al respecto es la reacción que presentan los anticuerpos contra carbohidratos del grupo A del EBGA y la N-acetil glucosamina de las glicoproteínas valvulares ${ }^{14}$. Estos autoanticuerpos persisten a título alto en el suero de los pacientes con valvulopatía 35 . Pese a ello, en animales de experimentación, los anticuerpos inducidos por el EBGA no reproducen el cuadro histológico de la $\mathrm{CRC}^{36}$. Esto sugiere que la respuesta inmune celular puede ser aún más importante que los autoanticuerpos en la patogenia de la enfermedad reumática, como sugiere una revisión reciente de este tema ${ }^{37}$. Otra de las hipótesis respecto de la patogenia de la enfermedad reumática propone que los superantígenos (SA) del EBGA participarían en la inducción de una respuesta autoinmune ${ }^{38}$. Los SA son mitógenos potentes que estimulan a los linfocitos $\mathrm{T}$ que poseen determinadas regiones variable beta (Vß) en su receptor antigénico ${ }^{39}$. Las células $\mathrm{T}$ que contienen alguno de estos elementos, podrían activarse por el SA bacteriano y desencadenar 0 perpetuar una afección autoinmune ${ }^{40}$. Recientemente, se ha descrito una expansión masiva de la expresión de regiones Vß2, Vß4 y Vß8 en linfocitos tonsilares humanos, postulándose que ello obedece precisamente al estímulo de SA del EBGA ${ }^{41}$. En una investigación de nuestro grupo sobre posibles efectos de SA en el infiltrado valvular de pacientes con CRC, nos pareció llamativa la persistencia de un conjunto pequeño de regiones Vß, en $73 \%$ de las válvulas investigadas, 21 a 49 años después del último episodio conocido de ERA ${ }^{17}$. Este tipo de restricción podría deberse a una respuesta inmune oligoclonal, antígeno específica, como sugieren los estudios moleculares recientes de la variabilidad y secuencia genética de las regiones $\mathrm{V} ß$ en linfocitos intralesionales ${ }^{42}$. Guilherme y cols han demostrado que los linfocitos $\mathrm{T}$ del infiltrado valvular presentan expansiones oligoclonales características de una respuesta inducida por antígeno in situ, incluida su restricción por moléculas del complejo mayor de histocompatibilidad $^{18}$. Esta serie de hallazgos nos llevaron a replantear la búsqueda de remanentes bacterianos en las válvulas de pacientes con CRC, encontrando positividad por PCR para ADN bacteriano en $80 \%(12 / 15)$ de los especímenes valvulares de pacientes con CRC. Estos resultados no parecen atribuibles a contaminación, tanto por la negatividad de las válvulas no reumáticas $(\mathrm{n}=6$ ), como de los blancos, que descartan una contaminación de reactivos (Figura 1-A y 2-A). No hemos encontrado ningún antecedente en la literatura respecto a la búsqueda de material bacteriano mediante PCR en los tejidos de pacientes con CRC, pero existen ahora importantes razones para replantear esta cuestión. Los antecedentes más relevantes proceden de los estudios de pacientes con artritis reactiva (ReA). En estos casos se desencadena una inflamación sinovial aguda en respuesta a una infección extraarticular por Chlamydia trachomatis, Yersinia u otros agentes infecciosos, la que ocasionalmente evoluciona hacia la cronicidad ${ }^{43}$. Las ReA habitualmente se han considerado una complicación posinfecciosa bacteriológicamente estéril, al igual que la enfermedad reumática. No obstante, se ha podido demostrar en la membrana sinovial de pacientes con ReA, no sólo la presencia de ADN de $\mathrm{C}$ trachomatis, sino también $\mathrm{ARN}$, lo que indica que el germen se encontraría viable al interior de la articulación afectada ${ }^{44,45}$. El significado de estas observaciones resta aún por precisarse, 
por cuanto la $\mathrm{C}$ trachomatis es un patógeno frecuente, que se ha detectado ocasionalmente mediante PCR, en individuos con otras artropatías inflamatorias, con artrosis e incluso en biopsias sinoviales de 2 de 30 voluntarios sanos ${ }^{46}$. No obstante, Chen y cols, recientemente emplearon sondas de ARNr 23S pan-bacteriano para buscar persistencia de gérmenes en el tejido sinovial de 81 pacientes: 42 con artritis reumatoide, 31 con artrosis y 8 con artropatías inflamatorias de diverso tipo, encontrando que todos fueron negativos. En contraste, detectaron positividad para $\mathrm{C}$ trachomatis en $33 \%$ de casos de ReA secundaria a este gérmen ${ }^{47}$. Esto sugiere que la detección de ARN bacteriano en los tejidos no es un hallazgo circunstancial, sino un hecho que se circunscribe a los casos de enfermedad inmune posinfecciosa. En la artropatía psoriática, una enfermedad que se ha vinculado al EBGA, se ha detectado mediante PCR la persistencia de ARN ribosomal del germen, hasta 21 años después del inicio de la enfermedad ${ }^{48}$.

La hipótesis de que el EBGA persiste en el tejido valvular de pacientes con CRC cobra ahora

\section{REFERENCIAS}

1. Chockalingam A, Prabhakar D, Dorairajan S, Priya C, Gnanavelu G, VenKatesan S et al. Rheumatic heart disease occurrence, patterns and clinical correlates in children aged less than five years. J Heart Valve Dis 2004; 13: 11-14.

2. Medina E, Contreras V, Valenzueia M. [Epidemiological aspects of chronic rheumatic diseases in Chile]. Rev Méd Chile 1987; 115: 889-93.

3. Oyonarte M, Montagna R, Braun S, Maiers E, Rojo P, Cumsille JF; Sociedad Chilena de Cardiología y Cirugía Cardiovascular. [Infectious endocarditis: morbi-mortality in Chile. Results of the National Cooperative Study of Infective Endocarditis (1998-2002)]. Rev Méd Chile 2003; 131: 237-50.

4. World Heart Organization (WHO/OMS). Rheumatic Fever and Rheumatic Heart Disease. Expert Group Study. Technical report series 923, Geneva, WHO 2004.

5. MarKowitz M. Observations on the epidemiology and preventability of rheumatic fever in developing countries. Clin Ther 1981; 4: 240-51. especial relieve, por cuanto se ha descrito que ciertas moléculas de ADN bacteriano que contienen dinucleótidos citosina-guanina no metilados (CpG), actúan como poderosos estimulantes de la respuesta inmune, induciendo un patrón de secreción de citoquinas tipo $\mathrm{T}$ helper 1 (Th1) 49,50, similar al descrito en la $\mathrm{CRC}^{51}$. La descripción reciente de estos dinucleótidos $\mathrm{CpG}$ en el genoma del EBGA, agrega especial interés a este hallazgo en pacientes con cardiopatía reumática ${ }^{52}$. No obstante, para certificar que el ADN bacteriano que detectamos en el tejido valvular de los pacientes, corresponde efectivamente a EBGA, resulta necesario secuenciar los productos de la reacción de PCR, labor en la que nuestro laboratorio se concentra actualmente.

Nuestros resultados sugieren una nueva perspectiva para interpretar la patogenia de la ERA y sus secuelas cardiovasculares. La identificación genética definitiva del EBGA en los tejidos cardíacos afectados pondría en evidencia una nueva modalidad patogénica de este agente bacteriano.

6. Stollerman G, Pearce I. The changing epidemiology of rheumatic fever and acute glomerulonephritis. Adv Inter Med 1968; 14: 201-39.

7. GuilHerme L, KaLL J. Rheumatic fever: From sore throat to autoimmune heart lesions. Int Arch Allergy Immunol 2004; 134: 56-64.

8. Нutтo J, Ayoub E. Cytoxicity of lymphocytes from patients with rheumatic carditis to cardiac cells in vitro. In: Streptococcal Diseases and Immune response. S.E. Read and J.B. Zabriskie, editors. Academic Press, New York 1980; 733-38.

9. ZabRISKIE J, FreImer J. An immunological relationship between the group A streptococcus and mammalian muscle. J Exp Med 1966; 124: 66178.

10. Yoshinaga M, Figueroa F, Wahid M, Marcus R, Suh E, ZABRISKIE J. Antigenic specificity of lymphocytes isolated from valvular specimens of rheumatic fever patients. J Autoimmun 1995; 8: 601-13.

11. Guilherme L, Cunha-Neto E, Coelho V, Snitcowsky R, Pomerantzefr P, Assis R et al. Human heart infiltrating T-cell clones from Rheumatic Heart Disease patients recognize both streptococcal and cardiac proteins. Circulation 1995; 92: 415-20. 
12. Behar S, Porcew S. Mechanisms of autoimmune disease induction: The role of the immune response to microbial pathogens. Arthritis Rheum 1995; 38: 458-76.

13. Dale J, Beachey E. Epitopes of streptococcal M proteins shared with cardiac myosin. J Exp Med 1985; 162: 583-91.

14. Goldstein I, HalPern B, Robert L. Immunological relationship between streptococcus A polysaccharide and the structural glycoprotein of heart valve. Nature 1967; 213: 44-7.

15. Marboe C, Knowles D, Weiss M, Fenoglo J. Monoclonal antibody identification of mononuclear cells in endomyocardial biopsy specimens from a patient with rheumatic carditis. Human Pathol 1985; 16: 332-38.

16. Kemeny E, Grieve T, Marcus R, Sareul P, Zabriskie J. Identification of mononuclear cells and $\mathrm{T}$ cells subsets in rheumatic valvulitis. Clin Immunol Immunopathol 1989; 52: 225-37.

17. Figueroa F, González M, Carrión F, Lobos C, Turner F, Lasagna $N$ et al. Restriction in the usage of variable beta regions in T-cells infiltrating valvular tissue from rheumatic heart disease patients. J Autoimmun 2002; 19: 233-40.

18. Guilherme L, Dulphy N, Douay C, Coelho V, CunhaNeto E, Oshiro S et aL. Molecular evidence for antigen driven immune response in cardiac lesions of rheumatic heart disease patients. Int Immunol 2000; 12: 1063-74.

19. FERRERI P. «Proceedings of the jones criteria workshop», The American Heart Association. Circulation 2002; 106: 2521-23.

20. Figueroa F, Fernández M, Valdés P. Prospective Comparison of Clinical and Echocardiographical Diagnosis of Rheumatic Carditis. Long-term Follow up of Patients with Subclinical Disease. Heart 2001; 85: 407-10.

21. WibRINK B, VAN DeR Hejden I. Detection of bacterial DNA in joint samples from patients with undifferentiated arthritis and reactive arthritis, using polymerase chain reaction with universal 16S ribosomal RNA primers. Arthritis Rheum 1998; 41: 535-43.

22. Moore J, MiLar B. A Rapid Molecular Assay for the Detection of Antibiotic Resistance Determinants in Causal Agents of Infective Endocarditis. J App Mic 2001; 90: 719-26.

23. MiLar B, Moore J. Molecular Diagnosis of Infective Endocarditis-A New Duke's Criterion. Scand J Infect Dis 2001; 33: 673-80.
24. Hiramatsu K, Harada K, Tsuneyama K, Sasaki M, FujtTa S, HASHIMOTO T ET AL Amplification and sequence analysis of partial bacterial 16S ribosomal RNA gene in gallbladder bile from patients with primary biliary cimhosis. J Hepatol 2000; 33: 9-18.

25. ZABRISKIE J. Rheumatic fever: The inter play between host, genetics and microbe. Circulation 1985; 71: 1077-86.

26. Vasan R, Selvaray N. 1999. Natural history of acute rheumatic fever. En: Narula J, Virmani R, Reddy K, Tandon R, (ed) Rheumatic Fever. American Registry of Pathology, Washington, D.C. 1999; 347-58.

27. Feinstein A, Stern E. Clinical effects of recurrent attacks of acute rheumatic fever: a prospective epidemiologic study of 105 episodes. J Chron Dis 1967; 20: 13-27.

28. Sto LeRman G. Rheumatic fever in the $21^{\text {st }}$ century. Clin Infect Dis 2001; 33: 806-14.

29. GibofsKy A, Kerwar S, Zabriskie J. Rheumatic fever. Rheum Dis Clin North Am 1998; 24: 237-59.

30. Thomson S, InNeS J. Haemolytic streptococci in the cardiac lesions of rheumatism. BJM 1940; 2: 733-36.

31. Watson RF, Hirst GK, LANCEFIELd RC. Bacteriological studies of cardiac tissues obtained at autopsy from eleven patients dying with rheumatic fever. Arthritis Rheum 1961; 4: 74-85.

32. MortimER E JR. Production of L forms of group A streptococci in mice. Proc Soc Exp Biol Med 1965; 119: 159-63.

33. Raizada V, Wimams Jr. RC, Chopra P, Gopinath N, Prakash K, Sharma K et al. Tissue distribution of lymphocytes in rheumatic fever valves as defined by monoclonal anti-T cell antibodies. Am J Med 1983; 74: 90-96.

34. Kaplan M, Meyeserian M. An immunological crossreaction between group-A streptococcal cells and human heart tissue. Lancet 1962; 1: 706-10.

35. Dudding D, Ayoud E. Persistence of streptococcal group A antibody in patients with rheumatic valvular disease. J Exp Med 1968; 128: 1081-92.

36. KaPLAN M. Streptococcal cross-reactions with tissue antigens: cardiac myofibres, smooth muscle, and heart valve fibroblasts. Significance for pathogenesis of rheumatic fever. En S.E. Read and J. B. Zabriskie (ed), Streptococcal diseases and the immune response. Academic Press Inc., 1980, New York.

37. Fae KC, Oshiro SE, Toubert A, Charron D, Kall J, GUILHERME L How an autoimmune reaction triggered by molecular mimicry between streptococcal 
M protein and cardiac tissue proteins leads to heart lesions in rheumatic heart disease. J Autoimmun 2005; 24: 101-9.

38. Carrión F, Fernández M, Iruretagiyena M, Coelho Andrade L, Odete-Hilario M, Figueroa F. Selective depletion of Vbeta2+CD8+ T cells in peripheral blood from rheumatic heart disease patients. J Autoimmun 2003; 20: 183-90.

39. Misfeldt M. Microbial superantigens. Infect Immun 1990; 58: 2409-12.

40. MARRACK P, KaPPiER J. The staphylococcal enteroxins and their relatives. Science 1990; 248: 70511.

41. Bernal A, Proft T, Fraser J, Posnett D. Superantigens in human disease. J Clin Immunol 1999; 19: 149-57.

42. Guilherme L, Cunha-Neto E, Tanaka A, Dulphy N, Toubert A, KaLL J. Heart-directed autoimmunity: the case of rheumatic fever. J Autoimmun 2001; 16: 363-7.

43. Sieper J, Kingsley G. Recent advances in the pathogenesis of reactive arthritis. Immunol Today 1996; 17: 160-3.

44. Branigan P, Gerard H, Hudson A, Schumacher H Jr, Pando J. Comparison of synovial tissue and synovial fluid as the source of nucleic acids for detection of Chlamydia trachomatis by polymerase chain reaction. Arthritis Rheum 1996; 39: 1740-6.

45. Gerard H , Branigan P, Schumacher H Jr, Hudson A. Synovial chlamydia trachomatis in patients with reactive arthritis / Reiter's syndrome are viable but show aberrant gene expression. J Rheumatol 1998; 25: 734-42.

46. Schumacher H Jr, Araysi T, Crane M, Lee J, Gerard H, Hudson A ET al. Chlamydia trachomatis nucleic acids can be found in the synovium of some asymptomatic subjects. Arthritis Rheum 1999; 42: 1281-84.

47. Chen T, Luukkaienen R, Mottonen T, Jalava J, RoIvainen A, ToIvanen P. Failure to detect bacterial DNA in synovial tissue from patients with inflammatory arthritis by PCR with pan bacterial 23S rRNA primers. Arthritis Rheum 1999; 42: S1047.

48. Wang Q, Vasey F, Mahfood J, Valeriano J, KaniK K, ANDERSON B ET AL. V2 regions of $16 \mathrm{~S}$ ribosomal RNA used as a molecular marker for the species identification of streptococci in peripheral blood and synovial fluid from patients with psoriatic arthritis. Arthritis Rheum 1999; 42: 2055-9.

49. HeEg K, ZimmermanN S. CpG DNA as a Th1 trigger. Int Arch Allergy Immunol 2000; 121: 87-97.

50. Krieg A. The role of CpG motifs in innate immunity. Curr Opin Immunol 2000; 12: 35-43.

51. Guilherme L, Cunha-Neto E, Coelho V, Snitcowsky R, ABel L, LóPEZ A ET AL. Rheumatic heart disease: proinflamatory cytokines play a role in the progression and maintenance of valvular lesions. Am J Pathol 2004; 165: 1583-91.

52. С HAтешеR S, Котв M. Preferential stimulation of human lymphocytes by oligodeoxynucleotides that copy DNA CpG motifs presents in virulent genes of group A streptococci. Eur J Immunol 2000; 30: 993-1001.

Agradecimientos

Expresamos nuestros agradecimientos al Dr. Jacques Sany por alentarnos a realizar esta investigación. 